\title{
Structure and Bioactive Properties of Novel Textile Dyes Synthesised by Fungal Laccase
}

\author{
Jolanta Polak ${ }^{1, *}$, Kamila Wlizło ${ }^{1}$, Rebecca Pogni ${ }^{2}{ }^{\circledR}$, Elena Petricci ${ }^{2}{ }^{-}$, Marcin Grąz ${ }^{1}$, \\ Katarzyna Szałapata ${ }^{1}{ }^{\mathbb{D}}$, Monika Osińska-Jaroszuk ${ }^{1}{ }^{1}$, Justyna Kapral-Piotrowska ${ }^{3}{ }^{\circledR}$, \\ Bożena Pawlikowska-Pawlęga ${ }^{3}$ and Anna Jarosz-Wilkołazka ${ }^{1}$ (D) \\ 1 Department of Biochemistry and Biotechnology, Institute of Biological Sciences, Maria Curie-Skłodowska \\ University, Akademicka 19, 20-033 Lublin, Poland; kamila.wlizlo@poczta.umcs.lublin.pl (K.W.); \\ graz@poczta.umcs.lublin.pl (M.G.); katarzyna.szalapata@poczta.umcs.lublin.pl (K.S.); \\ monika.osinska-jaroszuk@poczta.umcs.lublin.pl (M.O.-J.); anna.wilkolazka@poczta.umcs.lublin.pl (A.J.-W.) \\ 2 Department of Biotechnology, Chemistry and Pharmacy, University of Siena, Via A. Moro 2; 53100 Siena, \\ Italy; rebecca.pogni@unisi.it (R.P.); elena.petricci@unisi.it (E.P.) \\ 3 Department of Functional Anatomy and Cytobiology, Institute of Biological Sciences, Maria \\ Curie-Skłodowska University, Akademicka 19, 20-033 Lublin, Poland; \\ justyna.kapral-piotrowska@poczta.umcs.lublin.pl (J.K.-P.); \\ bozena.pawlikowska-pawlega@poczta.umcs.lublin.pl (B.P.-P.) \\ * Correspondence: jpolak@poczta.umcs.lublin.pl; Tel.: +48-81-537-50-51
}

Received: 21 February 2020; Accepted: 15 March 2020; Published: 17 March 2020

\begin{abstract}
Novel sustainable processes involving oxidative enzymatic catalysts are considered as an alternative for classical organic chemistry. The unique physicochemical and bioactive properties of novel bio-products can be obtained using fungal laccase as catalyst. Among them are textile biodyes synthesised during oxidation of substrates belonging to the amine and methoxy organic derivatives. The process of synthesis occurs in mild conditions of $\mathrm{pH}$, temperature, and pressure, and without using harmful oxidants. The effect of fungal laccase activity on the substrates mixture transformation efficiency was analysed in terms of antimicrobial dye synthesis on a large scale. Three new phenazine dyes, obtained in the presence of laccase from Cerrena unicolor, were studied for their structure and properties. The phenazine core structure of the products was a result of tri-molecular transformation of aminomethoxybenzoic acid and aminonaphthalene sulfonic acid isomers. One of the compounds from the synthesised dye, namely 10-((2-carboxy-6-methoxyphenyl)amino)-11-methoxybenzo[a]phenazine-8-carboxylic acid, was able to inhibit the growth of Staphylococcus aureus. The high concentration of substrates $(5 \mathrm{~g} / \mathrm{L})$ was efficiently transformed during $72 \mathrm{~h}$ in the mild conditions of $\mathrm{pH} 4$ with the use of laccase with an activity of $200 \mathrm{U}$ per $\mathrm{g}$ of the substrates mixture. The new bioactive dye exhibited excellent dyeing properties with concomitant antibacterial and antioxidative activity. The proposed enzyme-mediated synthesis represents an alternative eco-friendly route for the synthesis of novel antimicrobial compounds with high importance for the medical textile industry.
\end{abstract}

Keywords: biotransformation; laccase; phenazine; bioactive dyes; antimicrobial; antioxidative compounds

\section{Introduction}

Laccases, especially those of fungal origin, are universal, cheap, and easy to handle biocatalysts with several applications [1,2]. The synthesis of the long list of novel organic compounds, e.g., substituted imidazoles, cyclohexenes, phenoxazines, or azo dyes, is possible in one-pot reactions via laccase-mediated homo- or heteromolecular transformations of different substrates belonging to the 
amino-, methoxy-, phenoxy-benzene or -naphthalene derivatives [3]. The compounds mentioned above, especially those belonging to phenazines or phenoxazines, are very promising due to their possible bioactivity and dyeing properties. In nature, phenazines with broad bioactivity are products of the idiophase of different bacteria, especially from Pseudomonas and Streptomyces strains [4,5]. Both natural and synthetic phenoxazines and phenazines known from the literature exhibit biological activities such as antibacterial [6-8], antitumoral [9], antiproliferative [10], and antioxidant [11] properties. The chemical route of phenazine synthesis requires the use of coupling agents and additives such as benzene, $\mathrm{BBr}_{3}, \mathrm{DMF}$, and various other harsh, toxic, and mutagenic compounds [12]. In contrast to the chemical synthesis, phenoxazine and phenazine compounds can be easily obtained through the biocatalysis due to the action of fungal or bacterial laccase and the use of aminophenolic precursors [13-16]. Phenoxazines can be synthesised in laccase-mediated homomolecular coupling reactions of different ortho-aminophenols or ortho-aminonaphtalenes [13,14], whereas phenazines can be obtained through the heteromolecular transformation of phenol derivatives with aromatic amines $[15,17]$. The synthesis of new substances with the phenazine core is highly desirable, as it may result in the discovery of new chemicals with new properties, including bioactivity. Herein, we report the structure of three different phenazines obtained through the laccase-mediated heteromolecular transformation of aminomethoxybenzoic acid with three isomers of aminonaphthalene sulfonic acid. Red-coloured products were obtained and one of them was found to exert an antibacterial effect against a Staphylococcus aureus strain. All these processes are very promising alternatives to classical organic synthesis having many disadvantages, such as the use of harsh reaction conditions as well as harmful and toxic organic additives. In contrast, during the laccase-mediated synthesis of novel organic compounds, the main co-substrate is oxygen and the only waste by-product is water, which renders this process "green".

The aim of this study was to synthesise red-coloured dyes, displaying dyeing, antioxidative, and even antimicrobial properties, in the fungal laccase-mediated eco-friendly process. The process optimisation included the selection of (1) an optimal value of $\mathrm{pH},(2)$ concentrations of substrates and their molar ratios, and (3) biocatalyst activity as the key parameters for the enzymatic process implementation in the industry. To our knowledge, this is the first "de novo" synthesised compound with both antioxidative and antimicrobial properties obtained by the use of fungal laccase as the catalyst. From this point of view, fungal laccase can be considered as a useful biocatalyst for the synthesis of bioactive dyes.

\section{Results}

2.1. Electrochemical and Kinetic Parameters of Substrates and Their Reactivity during Oxidation with Fungal Laccase

Four different substrates belonging to benzene (substrate $A$ ) and naphthalene derivatives (substrates B1, B2, and B3) were analysed as potential substrates for LAC-mediated oxidation (Figure 1).

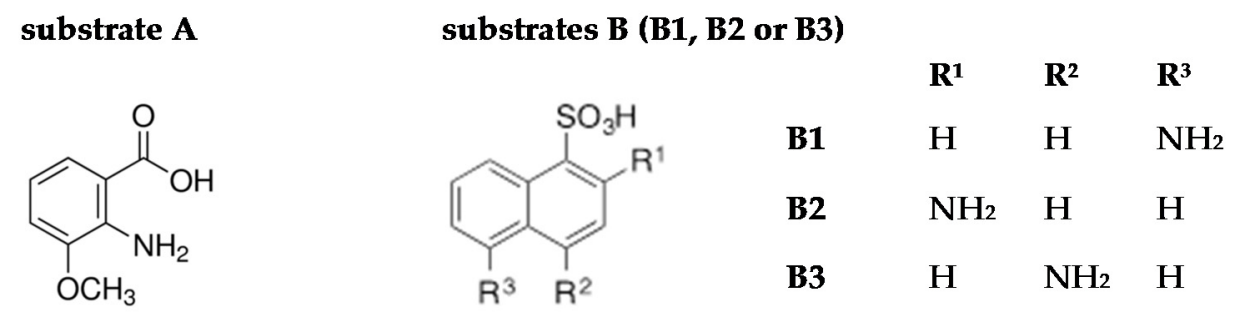

Figure 1. Structure of substrates used for laccase (LAC)-mediated heteromolecular transformations. $\mathrm{R}$ - the designation of specific substituents hydrogen atom $(\mathrm{H})$ or amine group $\left(\mathrm{NH}_{2}\right)$ in individual places. 
Three different parameters, i.e., the electrochemical potential, oxygen demand, and kinetic constant $K_{\mathrm{M}}$ were analysed as key factors playing an important role during the enzymatic oxidation of different substrates to reactive radicals. Substrate A belonging to the carboxylic acid and possessing an amine and methoxy group at position 2 and 3, respectively, has both the lowest oxidation potential and the lowest value of $K_{\mathrm{M}}$ with simultaneously the highest oxygen demand observed during its oxidation by LAC (Table 1).

Table 1. Electrochemical and kinetic parameters of tested substrates.

\begin{tabular}{|c|c|c|c|c|}
\hline $\begin{array}{l}\text { Substrates } \\
\text { Acronyms }\end{array}$ & $\begin{array}{c}\text { Oxygen Uptake }{ }^{1} \\
\left(\text { nmol O}_{2} / \mathrm{min} / \mathrm{mL}\right)\end{array}$ & $\underset{(\mathrm{V})}{E_{\mathrm{pa}}{ }^{1}}$ & $\begin{array}{c}\lambda \\
(\mathrm{nm})\end{array}$ & $\begin{array}{c}K_{\mathrm{M}} \\
(\mathrm{mM})\end{array}$ \\
\hline $\mathrm{A}$ & 352.29 & 0.805 & 490 & 1.58 \\
\hline B1 & 134.98 & 0.879 & 460 & 3.94 \\
\hline B2 & 23.31 & 1.021 & 495 & 17.00 \\
\hline B3 & 34.24 & 0.913 & 495 & 5.38 \\
\hline
\end{tabular}

1 The determination of oxygen uptake and oxidation potential (vs. NHE) were performed at the Na-tartrate buffer $\mathrm{pH} 4.5$ value for $1 \mathrm{mM}$ concentration of each substrate.

In contrast to the 2-amino-3-methoxycarboxylic acid (substrate A), aminonaphthalene derivatives (substrates B1, B2, and B3) were much more slowly oxidised by LAC during the homomolecular reaction. The lack of additional reactive substituents, especially phenolic groups, resulted in an increase in the oxidation potential value and the $K_{\mathrm{M}}$ value, with a simultaneous decrease in oxygen uptake (Table 1). Moreover, the values of these parameters largely depend on the position of the amino group attached to the naphthalene core. Substrate B2, having the amino group in the ortho position in respect to the sulfonic group, was not effectively oxidised by LAC $\left(K_{\mathrm{M}}=17 \mathrm{mM}\right)$ due to the high value of the oxidation potential. The localisation of the amino group at positions 4 and 5 of substrates B 3 and $B 1$, respectively, in respect to the sulfonic group of naphthalene, led to the reduction of the oxidation potential and $K_{\mathrm{M}}$ values. Consequently, the possible oxidation of these substrates by LAC is confirmed by the lower value of $K_{\mathrm{M}}$ corresponding to $5.38 \mathrm{mM}$ and $3.94 \mathrm{mM}$, respectively (Table 1).

\subsection{Heteromolecular Transformation of Substrates}

Products obtained from heteromolecular transformation of substrate A with one from the substrate B were intensively coloured and exhibit maximum absorption around $495 \mathrm{~nm}$ for compounds AB1 and $\mathrm{AB} 2$ and at $505 \mathrm{~nm}$ for compound $\mathrm{AB} 3$ at optimal $\mathrm{pH}$ of 4.5, 4 and 4.5 respectively, and therefore can be considered as textile dyes. Moreover, different colouration of the end-product was observed at $\mathrm{pH} 5.5$, which confirmed the optimal value of $\mathrm{pH}$ in the range from 4 to 4.5 (Figure 2a).

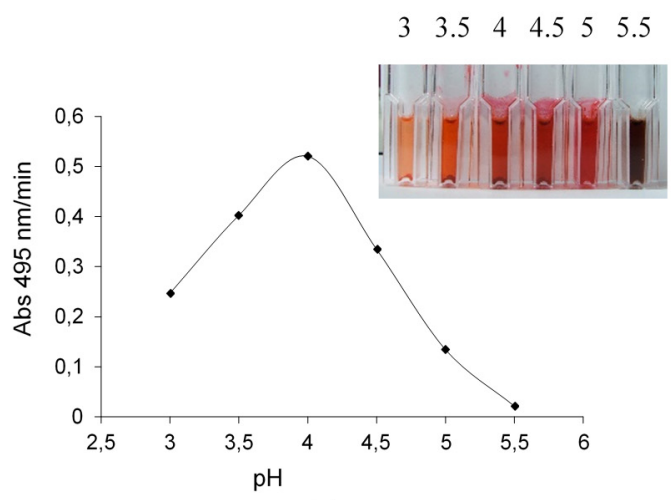

(a)

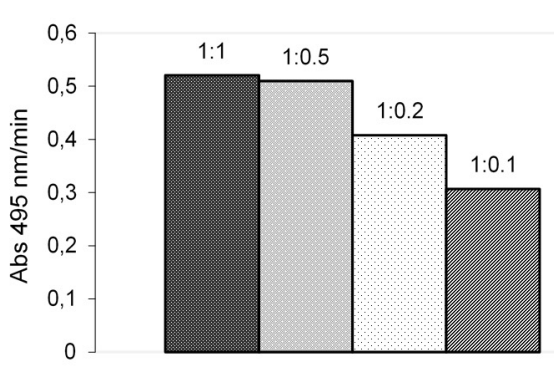

(b)

Figure 2. Influence of the $\mathrm{pH}$ value (a) and the molar ratio of substrates A and B2 (1:1, 1:0.5, 1:0.2, 1:0.1-A:B2 molar ratio) (b) on the rate of phenazine AB2 synthesis mediated by LAC. 
No differences in the spectrum and TLC chromatograms of the products obtained were noted in the presence of $10 \%$ of the organic solvents. Therefore, the optimal transformation mixture did not contain these solvents, which confirms the "green and more ecological character" of the transformation process.

In the optimal buffer conditions, the effect of a different molar ratio of A and B on the rate of transformation into a novel product was investigated. The best rate of biotransformation was obtained during oxidation of the equimolar ratio of substrate A with substrate B2 (Figure $2 b$ ) as well as substrate $A$ with substrates $B 3$ or $B 1$. In such conditions, the isolated yields of the main products $A B 1, A B 2$, and AB3 estimated from the actual and theoretical yield and based on stoichiometric calculations were in the range from 19 to $27 \%$, depending on the product obtained (Table 2).

Table 2. Heteromolecular coupling reactions between substrate I (substrate A) and substrate II (substrate B1, B2 or B3), mediated by fungal LAC.

\begin{tabular}{cccc}
\hline Substrate I & Substrate II & Reaction $\mathbf{p H}$ Value & Isolated Yields (\%) \\
\hline A & B1 & 4.5 & 19 \\
A & B2 & 4 & 25 \\
A & B3 & 4.5 & 27 \\
\hline
\end{tabular}

Based on the HPLC analysis of the transformation mixture (monitored at $500 \mathrm{~nm}$ ), it can be concluded that low yield of the main dye is due to the presence of other different orange-coloured products arising during the transformation, with lower intensity, which have not been isolated and analysed to assess their molecular weight as well as bioactive properties (Figure 3).

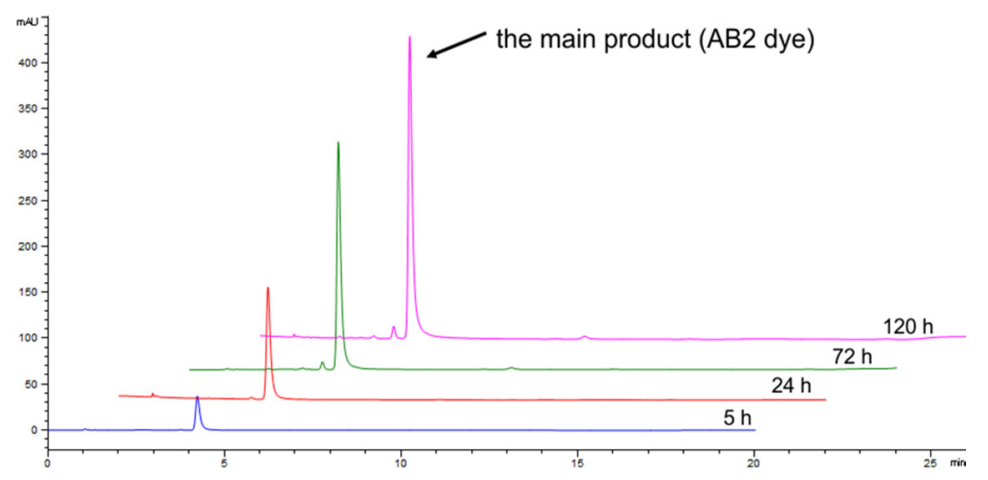

Figure 3. HPLC chromatograms of the transformation mixture detected at $500 \mathrm{~nm}$ containing the main product of the AB2 dye (absorption units, $\mathrm{mAU}$ ) synthesised after 5, 24, 72, and $120 \mathrm{~h}$ of $5 \mathrm{~g} / \mathrm{L}$ mixture of $\mathrm{A}$ and $\mathrm{B} 2$ substrates (methanol fraction).

The effect of LAC activity ranging from 12.5 to $500 \mathrm{U} / \mathrm{g}$ was checked in terms of the potential upscaling of the AB2 dye synthesis process. LAC was also used for the transformation of higher concentrations of the substrates $(1,5$, and $10 \mathrm{~g} / \mathrm{L}$ ) within $48 \mathrm{~h}$. Based on the value of dye absorbance (at $500 \mathrm{~nm}$ ) and the main AB2 compound peak area, the optimal LAC activity was around $200 \mathrm{U} / \mathrm{g}$ for all tested concentrations of substrates A and B2 (Figure 4). 

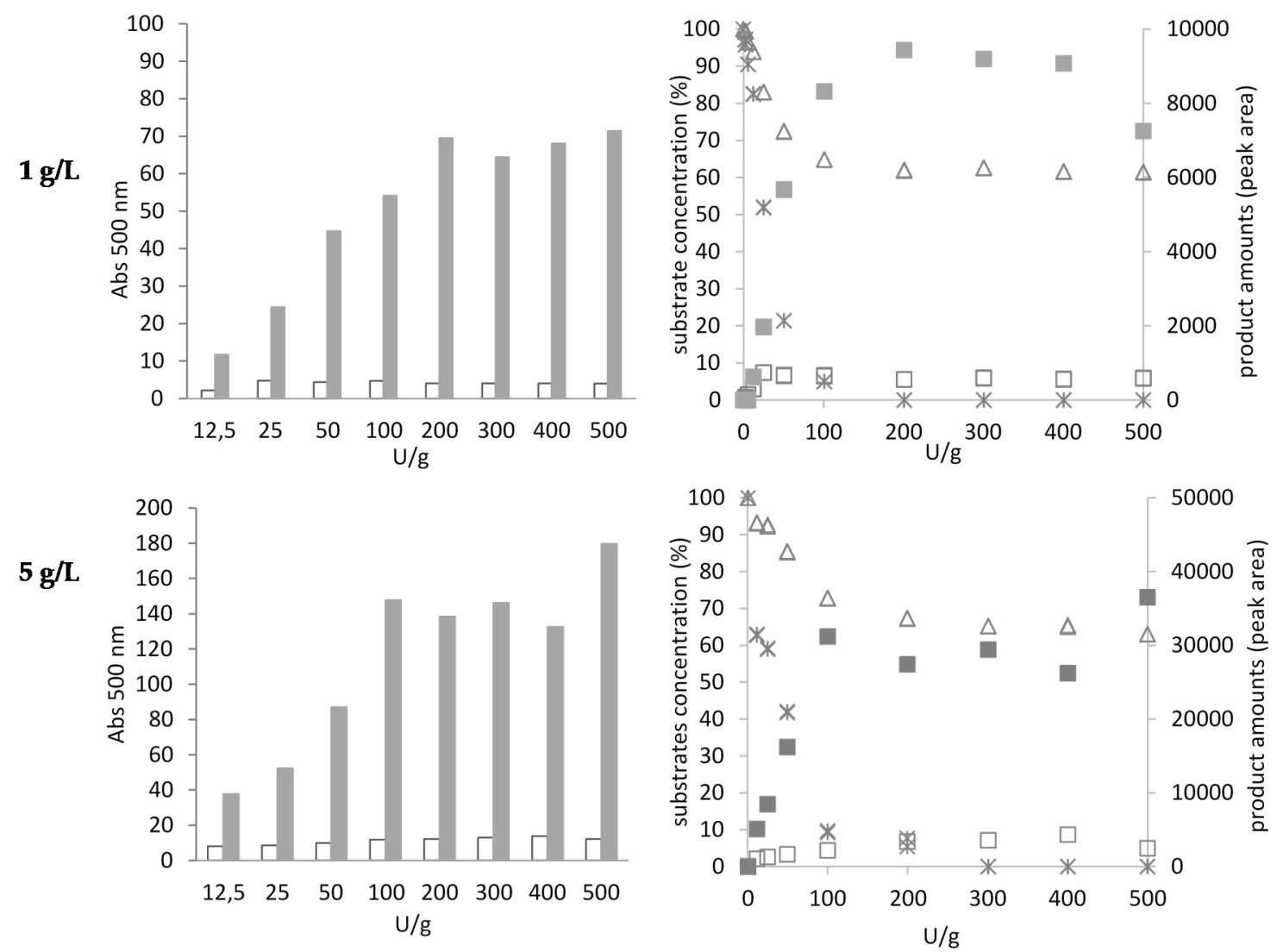

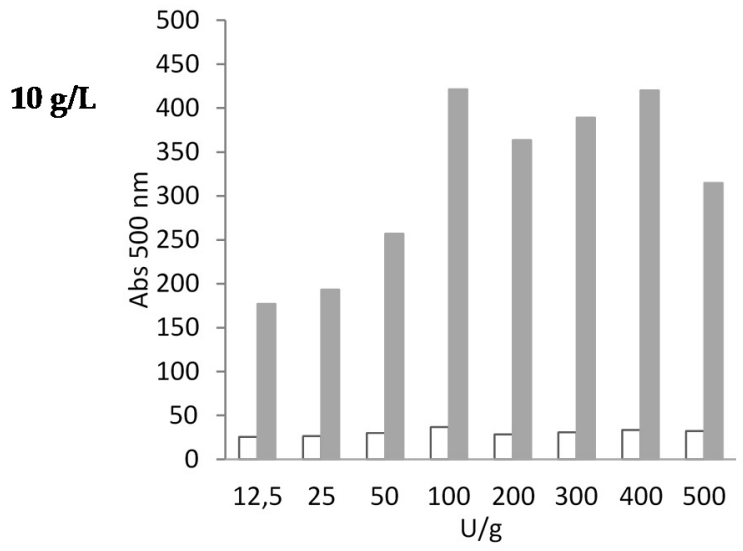

(a)

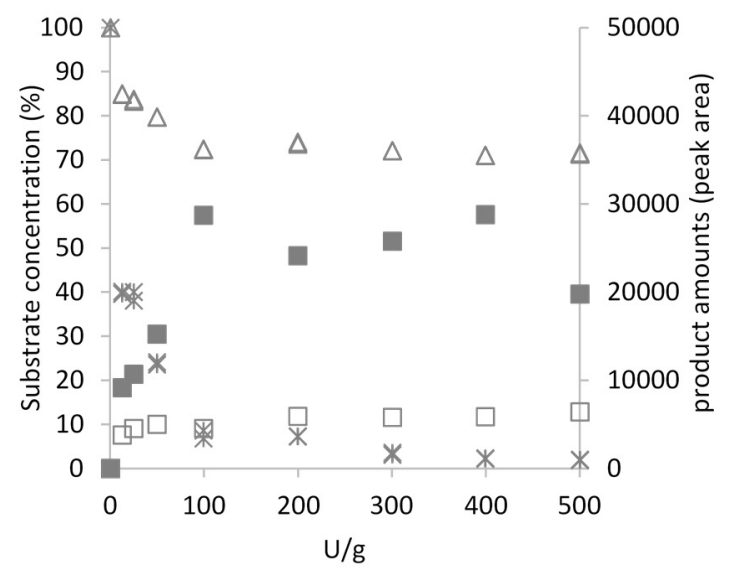

(b)

Figure 4. Effect of LAC activity (U/g) on the amount of AB2 dye expressed as the absorbance at $500 \mathrm{~nm}$, dissolved in methanol (filled bars) and water (empty bars) fractions (a) and the peak area obtained from HPLC analysis (b) of methanol (filled squares) and water (empty squares) fractions of products after 48-h oxidation. Residual concentrations of A and B2 substrates (\%) were analysed using HPLC; substrates are marked as follows: substrate A residual concentration (\%)—cross; substrate B2 residual concentration (\%)—-triangle.

The detailed analysis of the transformation of $5 \mathrm{~g} / \mathrm{L}$ of the A and B2 mixture was performed for 5 days using LAC with the final activity of $200 \mathrm{U}$ per gram of substrate (Figure 5). Based on the HPLC analysis, it can be concluded that the nearly total transformation of substrate A occurred within $72 \mathrm{~h}$ (Figure 5). 


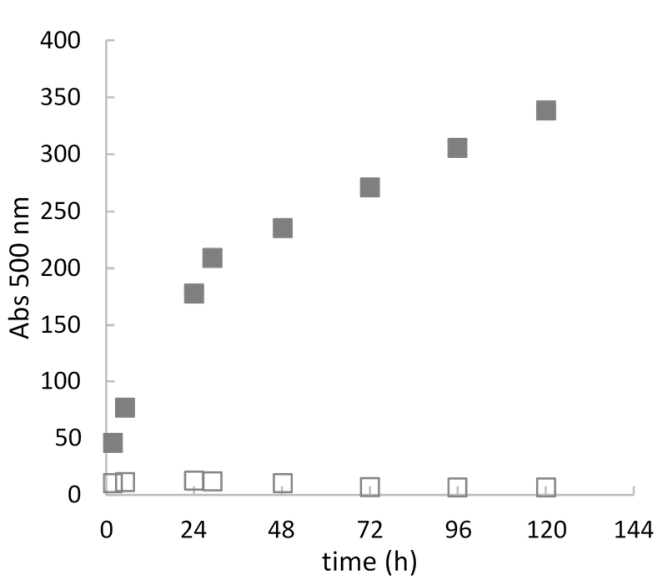

(a)

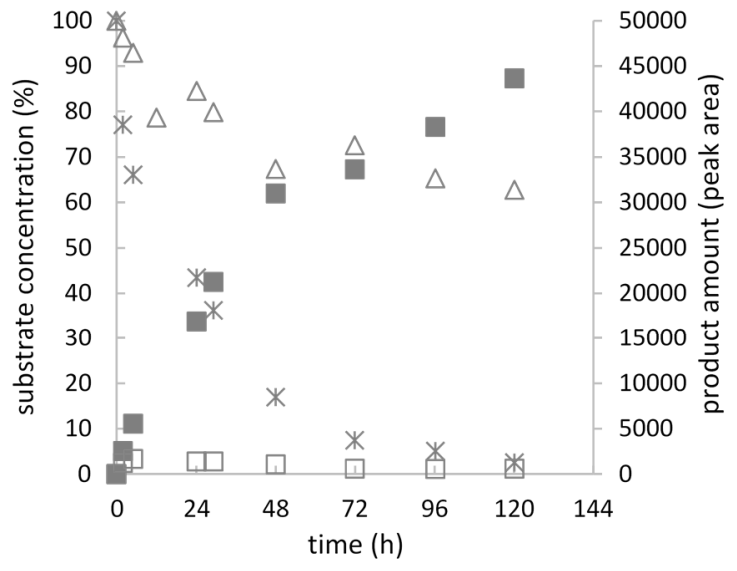

(b)

Figure 5. Amount of AB2 dye obtained from substrate A and B2 equimolar oxidation (total concentration of mixture $5 \mathrm{~g} / \mathrm{L}$ ) using fungal LAC ( $200 \mathrm{U} / \mathrm{g}$ ) during 5 days of transformation. The amount of the dye was expressed as total absorbance at $500 \mathrm{~nm}$ (a) and AB2 dye peak area obtained from HPLC analysis (b) of water and methanol fractions. Residual concentration of A and B2 substrates (\%) was analysed using HPLC. Substrates and products are marked as follows: AB2 dye fraction dissolved in water-empty square; AB2 dye fraction dissolved in methanol-filled square; substrate A residual concentration (\%)-cross; substrate B2 residual concentration (\%)-triangle.

After this time, an increase in the amount of the product was still observed (both absorbance and peak area of the main compound of the AB2 dye, which was probably caused by non-enzymatic coupling reaction of intermediates.

\subsection{Characteristics of Products Obtained}

\subsubsection{Structure Analysis}

Products obtained during the cross-coupling reaction between the equimolar concentrations of substrate $A$ and substrates $B 1, B 2$, or B3, namely AB1, AB2, and AB3, respectively, were purified by silica gel flash chromatography and characterised by IR, NMR (Table S1), and UV-Vis spectroscopy and mass spectrometry. As shown in Figure 5, the oxidation of the substrates probably led to the formation of substituted phenazines with a "head to head" framework (Figure 6).

Depending on the substrate B isomer used for the heteromolecular oxidation in the presence of substrate A, four different trimolecular compounds with different solubility in water were obtained during the reaction (Figure 6). The kinetic parameters corroborate the structure of the phenazines obtained. In the case of the B2 isomer, two different products, namely AB2a (10-((2-carboxy-6-methoxy phenyl)amino)-11-methoxybenzo[a]phenazine-8-carboxylic acid) and AB2b (10-((2-carboxy-6-methoxyphenyl)amino)-11-hydroxybenzo[a]phenazine-8-carboxylic acid), were detected during the HPLC-MS analysis. The ES mass analysis of AB2a and AB2b showed peaks at $m / z 456$ and $470[\mathrm{M}+\mathrm{H}]^{+}$, respectively, in positive mode and peaks at $m / z 454$ and $468[\mathrm{M}-\mathrm{H}]^{-}$, respectively, in negative mode. The ES mass spectra of the AB1 product (10-((2-carboxy-6-methoxyphenyl)amino)-11-methoxy-4-sulfobenzo[a]phe nazine-8-carboxylic acid), and the AB3 product (10-((2-carboxy-6-methoxyphenyl)amino)-11-methoxy5-sulfobenzo[a]phe-nazine-8-carboxylic acid) showed the peaks at $m / z 550$ in positive mode and at $m / z$ $548[\mathrm{M}-\mathrm{H}]^{-}$in negative mode. 


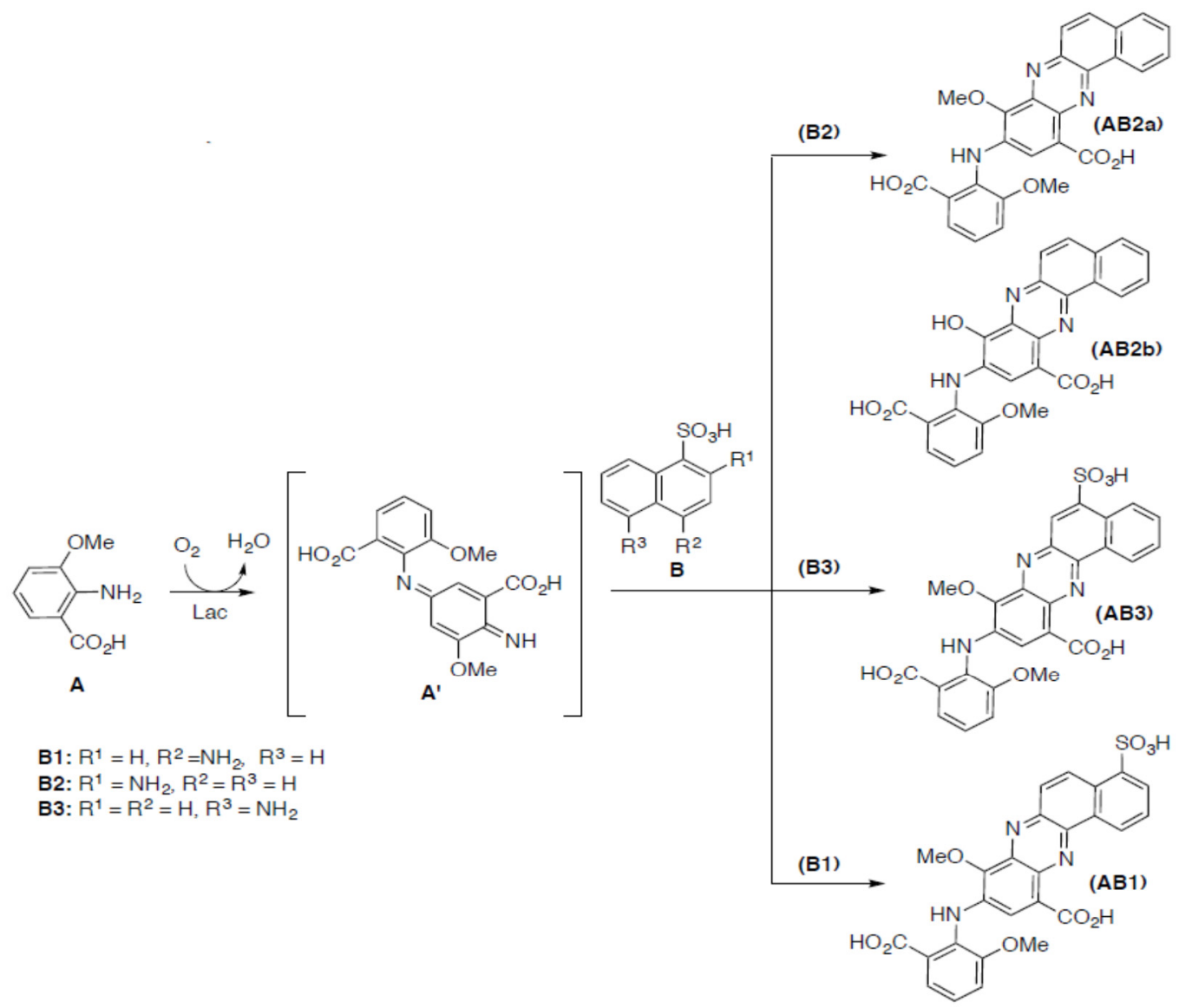

Figure 6. Proposed pathway of synthesis of phenazines (AB1, AB2a, AB2b, and AB3) as a result of LAC-mediated heteromolecular coupling reactions of aminomethoxycarboxylic acid (A) with three different isomers of aminonaphthalene (B1, B2, and B3). Acronyms of substrates and products have been bolded.

\subsubsection{Antioxidative Properties of Phenazine Dyes}

The antioxidative properties of phenazines were evaluated using a chemiluminescence method due to the intensive red colouration of dyes, which can interfere with the DPPH or ABTS assays, and therefore they are not useful for these purposes. All the tested dyes exhibited antioxidative potential with an $\mathrm{EC}_{50}$ value in the range from 0.44 to $0.63 \mathrm{mg}$ per $\mathrm{mL}$ (Table 3).

Table 3. Antioxidative properties of the phenazine dyes tested by chemiluminescence assay and expressed as $\mathrm{EC}_{50}$ values in comparison to the vitamin $\mathrm{C}$ and trolox as positive controls.

\begin{tabular}{cc}
\hline Tested Compound & $\mathrm{EC}_{\mathbf{5 0}}(\mathbf{m g} / \mathrm{mL})$ \\
\hline AB1 & 0.47 \\
AB2 & 0.44 \\
AB3 & 0.63 \\
vitamin C & 0.0047 \\
trolox & 0.00033 \\
\hline
\end{tabular}

\subsubsection{Antimicrobial Properties of Phenazine Dyes}

All phenazines were tested for their antimicrobial effect against E. coli and S. aureus strains using qualitative (agar diffusion test) and quantitative methods. In the case of the AB2 compound, it was tested as a mixture of $\mathrm{AB} 2 \mathrm{a}$ and $\mathrm{AB} 2 \mathrm{~b}$ products. From all the tested compounds, $\mathrm{AB} 2$ showed inhibition potential against $S$. aureus with a MIC value of $0.3 \mathrm{mg} / \mathrm{mL}$. Simultaneously, no antibacterial effect of the 
two other tested products, namely $\mathrm{AB} 3$ and $\mathrm{AB} 1$, was noted in the case of both the S. aureus and E. coli bacterial strains. Afterwards, the coloured AB2 product was applied for dyeing of wool fabric using $5 \%$ and $10 \%$ concentrations relative to the mass fibre (omf). The dyed wool fabrics were incubated in the presence of the S. aureus strain. After overnight incubation, inhibition of bacterial growth was possible to observe. The application of $10 \%$ of the AB2 dye caused nearly $100 \%$ growth inhibition of the $S$. aureus strain, whereas nearly $40 \%$ growth inhibition was noted at the concentration of $5 \%$. The antibacterial effect of the wool samples dyed with $10 \%$ AB2 was confirmed using the scanning electron microscopy (SEM). No bacterial colonies on the dyed wool fabrics were observed (Figure 7A,B) in contrast to the control non-dyed wool samples that contained visible single bacterial cells and colonies (Figure 7C,D).
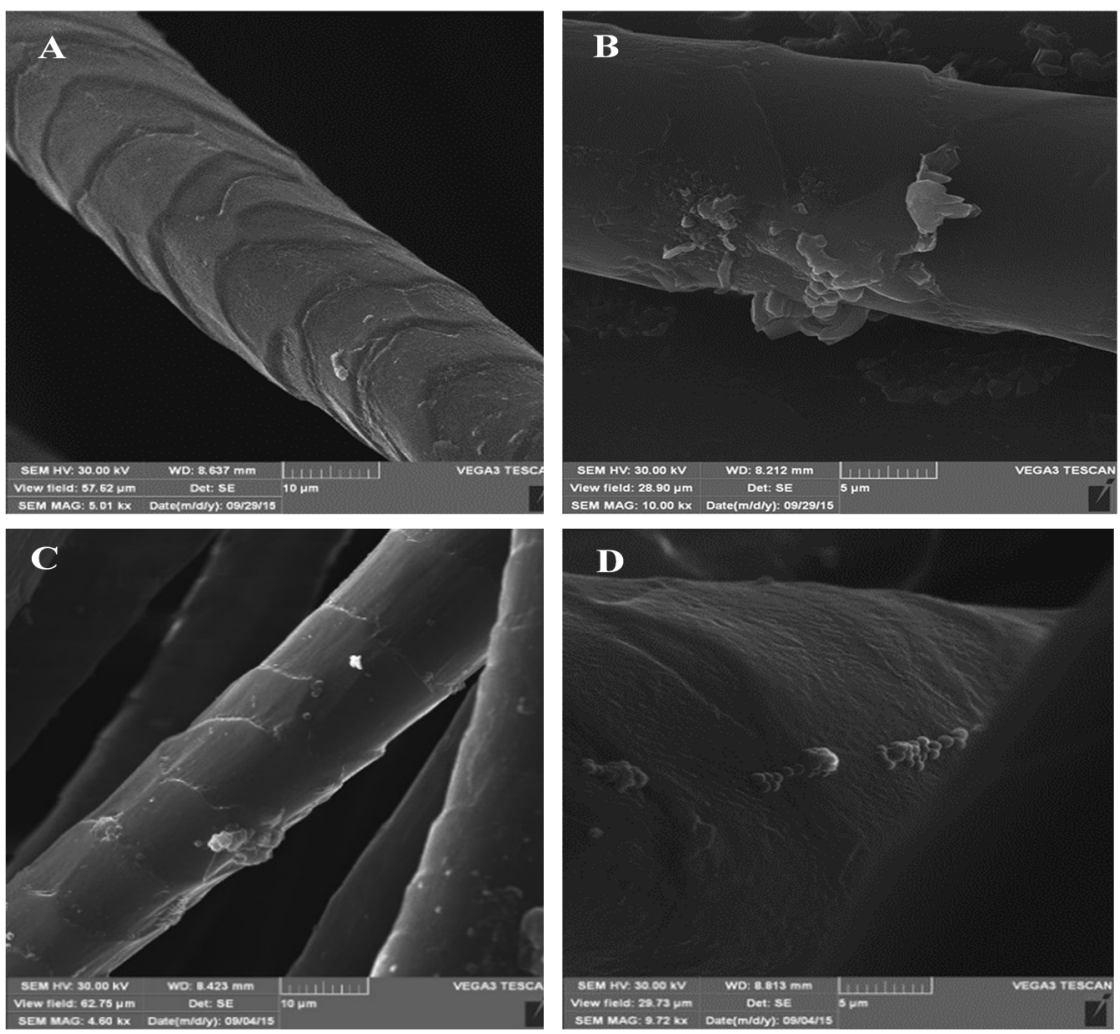

Figure 7. SEM pictures of wool fabrics dyed with $10 \%$ AB2 dye (A and $\mathbf{B}$ ) and corresponding control samples of non-dyed wool fabrics (C and D) after 24-h incubation with the S. aureus strain.

\subsubsection{Dying Properties of AB2 Dye}

Wool fibres dyed with $1 \%$ concentration of AB2 product were reddish coloured (Figure $8 b$ ). They were tested for their resistance to physicochemical factors, among them were artificial light, distilled water, washing at $40^{\circ} \mathrm{C}$, alkaline and acidic sweat, and dry and wet rubbing (Table 4). 


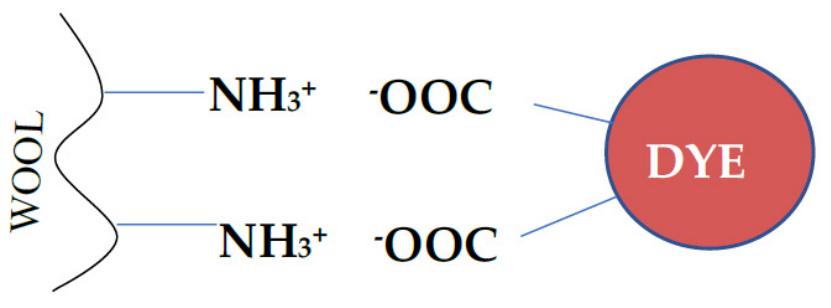

(a)

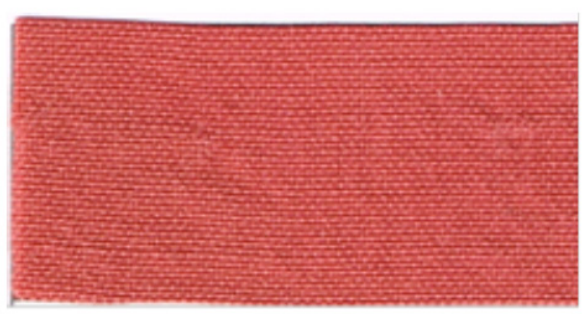

(b)

Figure 8. Scheme of dyeing mechanism (a) and sample of wool fabric dyed with $1 \%$ of AB2 compound (b), tested under dyeing quality.

Table 4. Colour fastness of wool fabric dyed with the AB2 dye at a concentration of $1 \%$.

\begin{tabular}{|c|c|c|c|}
\hline \multicolumn{2}{|c|}{ Tested Parameters of Colour Fastness } & \multirow{2}{*}{$\begin{array}{c}\text { Scale } \\
5\end{array}$} & \multirow{2}{*}{$\begin{array}{c}\text { ISO Standard } \\
\text { PN-EN ISO } \\
\text { 105-B02:2014-11 }\end{array}$} \\
\hline Artificial light ${ }^{1)}$ & a) & & \\
\hline Distilled water ${ }^{2)}$ & $\begin{array}{l}\text { a) } \\
\text { b) } \\
\text { c) }\end{array}$ & $\begin{array}{c}4 \\
4-5 \\
3-4\end{array}$ & $\begin{array}{c}\text { PN-EN ISO } \\
\text { 105-E01:2013-06 }\end{array}$ \\
\hline Washing $40{ }^{\circ} \mathrm{C}^{2)}$ & $\begin{array}{l}\text { a) } \\
\text { b) } \\
\text { c) }\end{array}$ & $\begin{array}{l}3-4 \\
4-5 \\
4-5\end{array}$ & PN-EN ISO 105-C06:2010 \\
\hline Alkaline sweat ${ }^{2)}$ & $\begin{array}{l}\text { a) } \\
\text { b) } \\
\text { c) }\end{array}$ & $\begin{array}{c}4 \\
3-4 \\
2-3\end{array}$ & $\begin{array}{c}\text { PN-EN ISO } \\
\text { 105-E04:2013-06 }\end{array}$ \\
\hline Acidic sweat ${ }^{2)}$ & $\begin{array}{l}\text { a) } \\
\text { b) } \\
\text { c) }\end{array}$ & $\begin{array}{l}4 \\
4 \\
3\end{array}$ & $\begin{array}{c}\text { PN-EN ISO } \\
\text { 105-E01:2013-06 }\end{array}$ \\
\hline Dry rubbing ${ }^{2)}$ & b) & $4-5$ & PN-EN ISO 105-X12:2005 \\
\hline Wet rubbing ${ }^{2)}$ & b) & $4-5$ & PN-EN ISO 105-X12:2005 \\
\hline
\end{tabular}

Tested AB2 dye showed good dyeing quality with moderate resistance in the case of alkaline sweat treatment (Table 4), which indicated the high dyeing potential of the tested compound as fabric dye.

\section{Discussion}

There is a growing need to discover new bioactive compounds due to the increased bacterial resistance to commonly used antibiotics. Literature data have so far described mainly natural dyes and naturally occurring phenols applied as laccase-assisted grafting agents of textile fibres with antimicrobial activity [18-21]. Moreover, only few papers concern the synthesis of novel LAC-mediated coupling products from phenolics or well-known antibacterial chemicals [3,22,23]. From the broad variety of antimicrobial compounds, phenazines, acting as both electron donors and acceptors, are able to inhibit the growth of bacteria, fungi, parasites, insects, malaria agents, and other organisms; hence, they are promising new bioactive compounds $[7,8]$. Our results presented in this paper indicate possible laccase-mediated synthesis of new trimolecular phenazines, which exhibit both bioactive and dyeing properties.

Three different mixtures of aminomethoxybenzoic acid and isomers of aminonaphthalenesulfonic acid were transformed by fungal laccase used as the catalyst, into products with very intense red colouration, which has already been mentioned in our previous paper [24]. It is already known, that 
the type of substituents (e.g., amino, methoxy) has a substantially higher impact on the reactivity of the tested substrates during homomolecular LAC-mediated oxidation than the type of the aromatic ring (benzoic and naphthalene) $[25,26]$. All of tested substrates possess at least one amino substituent, being a very reactive group for the LAC-mediated coupling reaction with other substrates to yield coloured products [26]. However, only substrate A, containing additional reactive methoxy group, was transformed into orange product about low toxicity during its homomolecular transformation and the dye obtained was able to colour natural fibres $[24,25,27]$. It was possible due to low values of redox potential and $K_{\mathrm{M}}$ of substrate $\mathrm{A}$, in contrary to the high values of both redox potential and $K_{\mathrm{M}}$ of aminonaphthalenesulfonic acids (substrates B). Despite that these three different structural isomers tested as a potential substrate of laccase possess one amino group each (the well-known reactive substituent involving in the LAC-mediated coupling reaction), low intensity coloured product was formed only in the case of substrate B1 homomolecular transformation [27,28]. Different effects of ring activation are observed in different isomers, what in the case of para compounds is responsible for the substrates redox potential lowering and the easier LAC-mediated oxidation [15,28].

Totally different products were obtained during heteromolecular biotransformation of substrate B isomers in the presence of substrate $\mathrm{A}$, and in these cases, the transformation mixtures were transformed into reddish coloured compounds after few minutes, which indicates the formation of new products [24]. The rate of each reaction at the different $\mathrm{pH}$ values exhibited a bell-shaped profile, with the maximal rate at $\mathrm{pH} 4$ in the case of substrates $\mathrm{A}$ and $\mathrm{B} 2$ mixture (Figure 2a) and at $\mathrm{pH} 4.5$ in the case of substrates A and B3 or substrates A and B1 mixtures (data not shown), which is consistent with the optimum $\mathrm{pH}$ profile of fungal laccases [29]. The present results reveal that substrate A, which can be directly oxidised by fungal laccase from the Cerrena unicolor strain due to its similar redox potential value, plays a key role in the heteromolecular coupling reaction with all tested aminonaphthalenesulfonic acids [30]. The low redox potential and the low value of $K_{\mathrm{M}}$ of substrate A suggest a probability of its dimerization into compound $\mathrm{A}^{\prime}$ as the first step of the LAC-mediated reaction (Figure 6). During this process, the amine radical A formed is involved in the coupling reaction on the para position of a second molecule (A) with the formation of the electrophilic quinondiimine intermediate $\left(A^{\prime}\right)$, which then reacts with a nucleophilic partner (B isomers) followed by intramolecular cyclization and methoxy group rearrangement. The putative reaction mechanism is reported in Figure 9.

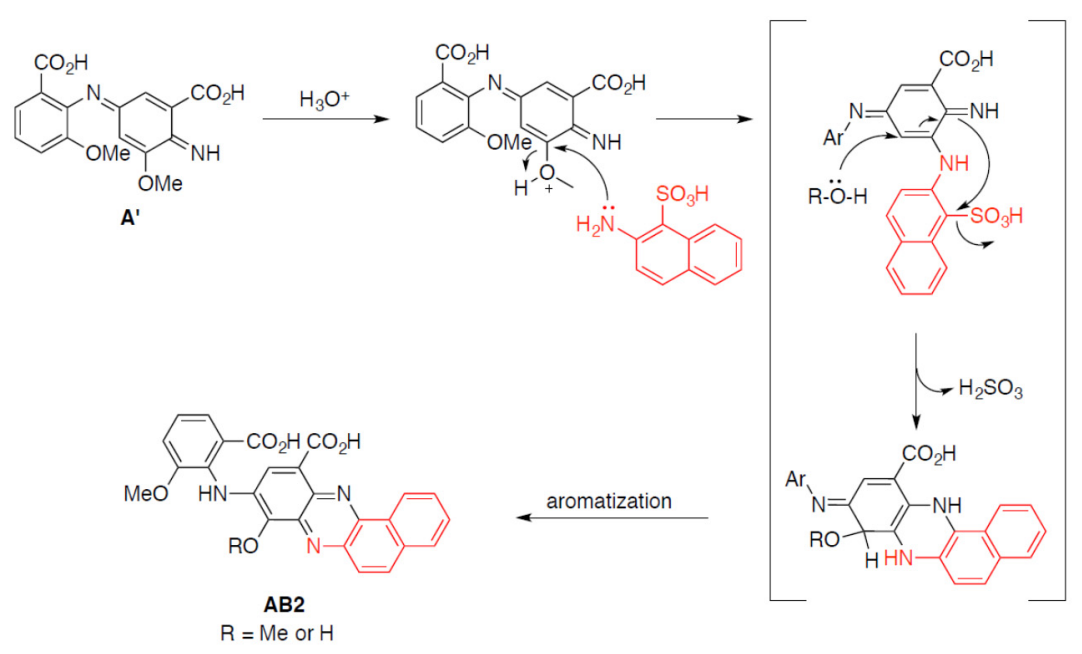

Figure 9. Proposed mechanism of heteromolecular coupling reaction of $A^{\prime}$ dimer and B2 substrate (marked in red) during AB2 dye synthesis.

Each isomer of substrate B is not readily oxidised by LAC, which is confirmed by its high oxidation potential and high $K_{\mathrm{M}}$ value. Therefore, it might be a target of a further coupling reaction with the radical form of compound $A^{\prime}$ in the second step of the reaction. During this process, a trimolecular phenazine structure is formed. Dye AB2, as a mixture of compounds AB2a and AB2b, exhibited 
lower solubility in water in contrast to the other products obtained, which can be explained by the lack of the sulfonic group in the structure. In the case of products obtained from the heteromolecular transformation of substrate A with isomers B3 or B1, similar water-soluble phenazines were obtained in both cases. The good water solubility of the $\mathrm{AB} 1$ and $\mathrm{AB} 3$ products was possible due to the presence of a sulfonic group at positions 4 and 5 , respectively.

The high concentration of substrates A and B2 mixture ( $5 \mathrm{~g} / \mathrm{L})$ applied for the transformation, yielded a total consumption of substrate A and nearly $50 \%$ consumption of $\mathrm{B} 2$ compound after $72 \mathrm{~h}$ of synthesis, what confirms our proposed structure of AB2 dye and mechanism of the synthesis. After 72 $\mathrm{h}$ of the reaction, an increase in the amount of the product AB2 was still observed (both absorbance and peak area of the main compound of the AB2 dye), which was probably caused by non-enzymatic coupling reaction of intermediates.

The antimicrobial and antioxidative properties of organic compounds very often are associated with the presence of hydroxy substituents acting as electron donors. Tested biodyes possess substituents rich in free electrons, such as methoxy and amine, which can be involved in their antioxidative potential, what is in agreement with our previous observation [11]. Bactericidal effect of AB2 dye against Staphylococcus aureus may result from the phenazine structure of dye, as well as from the presence of electron-donating groups. Good dyeing properties of tested AB2 dye may be the result of ionic bonds formation between the free amino groups of wool fibre and carboxyl groups of the dye (Figure 8a), what is in agreement with good dyeing ability of other dyes obtained from laccase-mediated oxidation of carboxylic acid as well as natural dyes [21,27].

This finding could shed new light on the potential uses of laccase in biocatalysis, especially in the eco-friendly synthesis of new bioactive compounds. The combination of the dyeing properties with antioxidative and antimicrobial activity of phenazines is very desirable in the textile industry. It prevents both fading of textiles and colonization of bacteria; therefore, it can be used for medical purposes, especially in hospitals with strict sanitary requirements as well as by immunocompromised patients [31].

\section{Materials and Methods}

\subsection{Catalyst}

The white rot fungus Cerrena unicolor (collection number FCL139, obtained from the Fungal Collection of the Biochemistry and Biotechnology Department of Maria Curie-Skłodowska University, Lublin, Poland) was the source of the extracellular laccase (LAC). LAC was obtained and purified using a previously described procedure [32]. LAC activity was determined using 2,2'-azino-bis(3-ethylbenzthiazoline-6-sulphonic acid (ABTS) as a substrate [33]. The reaction mixture contained $50 \mu \mathrm{L}$ of a LAC sample and $200 \mu \mathrm{L}$ of ABTS (2.5 mM final concentration) suspended in 750 $\mu \mathrm{L}$ of $0.1 \mathrm{M}$ sodium-tartrate buffer $\mathrm{pH}$ 3. Oxidation of ABTS was monitored spectrophotometrically for one minute at $414 \mathrm{~nm}\left(\lambda_{414}=36,048 \mathrm{M}^{-1} \mathrm{~cm}^{-1}\right)$. The activity of LAC was expressed in $\mathrm{U} / \mathrm{mL}$, where one unit (U) of the enzyme oxidised $1 \mu \mathrm{mol}$ of ABTS per $1 \mathrm{~min}$ at $25^{\circ} \mathrm{C}$.

\subsection{Characteristics of Substrates}

Chemicals, i.e., tartaric acid, 2-amino-3-methoxybenzenesulfonic acid (substrate A), ABTS and 5-aminonaphthalenesulfonic acid (5ANS, B1) were purchased from Sigma-Aldrich (St. Louis, MO, USA), 2-aminonaphthalenesulfonic acid (2ANS, B2) and 4-aminonaphthalenesulfonic acid (4ANS, B3) from Aldrich (Buchs, Switzerland and Munich, Germany, respectively). All chemicals were of analytical grade and were used without further purification. The kinetic constants $K_{M}$ of the aromatic substrates were monitored at $\mathrm{pH} 4.5$ of $0.1 \mathrm{M}$ sodium-tartrate buffer for each tested compound and fitted directly to the Michaelis-Menten equation (OriginLab software, Northhampton, MS, USA).

Oxygen uptake of the substrates was monitored during their homomolecular transformation by LAC with a biological oxygen monitor (YSI model 5300). The standard vessel contained $3 \mathrm{~mL}$ of the 
transformation mixture: $1 \mathrm{mM}$ concentration of the substrate in $0.1 \mathrm{M}$ sodium-tartrate buffer with $\mathrm{pH}$ 4.5. Each measurement was carried out for $3 \mathrm{~min}$ of the transformation and the oxygen uptake was calculated in $\mathrm{nmol} \mathrm{O}_{2} / \mathrm{mL} / \mathrm{min}$ according to Bernhardt et al. [34].

Cyclic voltammetry measurement of the substrates was carried out with a $\mu$ AUTOLAB type III potentiostat/galvanostat (Metrohm Autolab B.V., Utrecht, Netherlands) using a three-electrode cell containing a saturated $\mathrm{Ag} / \mathrm{AgCl} / \mathrm{KCl}_{\text {sat }}$ reference electrode, a platinum wire counter electrode, and a 2-mm diameter GC working electrode (all purchased from MTM-Anko, Kraków, Poland). The potential was scanned from -400 to $1500 \mathrm{mV}$ vs. $\mathrm{Ag} / \mathrm{AgCl} / \mathrm{KCl}_{\text {sat }}$ after holding the electrochemical system at the initial potential for $10 \mathrm{~s}$ and at the scan speed of $50 \mathrm{mV} / \mathrm{s}$. All measurements were done for $1 \mathrm{mM}$ substrates in $0.1 \mathrm{M}$ sodium tartrate buffer at $\mathrm{pH} 4.5$ in triplicate at room temperature. The measured potentials recorded vs. the $\mathrm{Ag} / \mathrm{AgCl} / \mathrm{KCl}_{\text {sat }}$ electrode were corrected by $+0.199 \mathrm{~V}$ to the normal hydrogen electrode (NHE).

\subsection{Heteromolecular Transformation of Substrates}

1-mL transformation mixtures containing an equimolar concentration of substrates $\mathrm{A}$ and $\mathrm{B}$ (B1, B2 or B3) with the final concentration of $1 \mathrm{mM}$ were transformed in buffered conditions $(0.1 \mathrm{M}$ sodium-tartrate buffer) with different values of $\mathrm{pH}$ (range from 3 to 5.5) using LAC with $1 \mathrm{U} / \mathrm{mL}$ final activity. The transformation of the substrates was monitored spectrophotometrically at a wavelength characteristic for each product for one minute and expressed as absorbance per minute. Additionally, the UV-Vis spectrum was recorded after the transformation of the substrates. At optimal values of $\mathrm{pH}$ during heteromolecular transformations, the substrates were oxidised by LAC in different molar ratios, wherein the maximal concentration of substrate A did not exceed $1 \mathrm{mM}$. Moreover, the transformations of the substrates were also performed in the presence of $10 \%$ of organic solvents such as methanol, acetonitrile, and ethyl acetate to find their influence on the formation of the main product and to improve the solubility of the precursors.

\subsection{Large-Scale Study of AB2 Dye Synthesis}

Three different concentrations of the mixtures of substrates A and B2 $(1,5$, and $10 \mathrm{~g} / \mathrm{L})$ at an equimolar ratio were oxidised by LAC with different activity ranging from $12.5 \mathrm{U} / \mathrm{g}$ to $500 \mathrm{U} / \mathrm{g}$ in $100 \mathrm{mM}$ tartrate buffer $\mathrm{pH}$ 4. The transformation mixtures were analysed using the HPLC method after 24 and $48 \mathrm{~h}$ to assess the optimal LAC activity during the first hours of substrate oxidation. Simultaneously, the absorbance of all the coloured products was monitored at $500 \mathrm{~nm}$ using a plate reader (Spark, Tecan, Grödig, Austria).

The oxidation of $5 \mathrm{~g} / \mathrm{L}$ of the $\mathrm{A}$ and B2 substrate mixture (equimolar ratio) using the optimal LAC activity ( $200 \mathrm{U} / \mathrm{g}$ ) and $100 \mathrm{mM}$ tartrate buffer $\mathrm{pH} 4$ was monitored for 5 days. At a specified time of oxidation $(2,5,24,29,48,72,96$, and $120 \mathrm{~h}), 1 \mathrm{~mL}$ of the transformation mixture containing $5 \mathrm{mg}$ of the substrate mixture was centrifuged at 13,000 rpm for $15 \mathrm{~min}$. The supernatant contained dissolved substrates and a fraction of the AB2 dye dissolved in water/buffer medium. The precipitate containing an insoluble AB2 product was dissolved in methanol (percentage up to 90\%). Both fractions, i.e., the precipitate and the supernatant, were analysed using HPLC to evaluate the increasing amount of the main product (AB2 dye) and the rate of transformation of substrates A and B2, respectively. Simultaneously, the absorbance of all the coloured products was monitored spectrophotometrically at $500 \mathrm{~nm}$ using a plate reader (Spark, Tecan, Grödig, Austria).

\subsection{HPLC Analyses}

High performance chromatographic analyses were performed using an Agilent 1260 Infinity chromatograph coupled with a DAD detector. The biotransformation of an equimolar ratio of substrates A and B2 was monitored by reverse-phase C18 HPLC using a Phenomenex Kinetex Polar $\mathrm{C} 18(4.6 \times 100 \mathrm{~mm}, 2.6 \mu \mathrm{m})$ column. The isocratic elution was prepared using methanol (eluent A) and $50 \mathrm{mM}$ formate buffer (eluent $\mathrm{B}$ ) in the ratio of $45 \%$ of eluent $\mathrm{A}(\mathrm{v} / \mathrm{v})$. The $\mathrm{pH}$ of eluent $\mathrm{B}$ was adjusted 
to 4.1 using $1 \mathrm{M} \mathrm{NaOH}$. The eluent flow rate was set at $1 \mathrm{~mL} \mathrm{~min}^{-1}$ and the separation column was maintained at $40^{\circ} \mathrm{C}$. Each 3- $\mu \mathrm{L}$ sample was injected using an autosampler. The total run time of each analysis was $20 \mathrm{~min}$. The elution of compounds was monitored at a wavelength of 280 and $500 \mathrm{~nm}$. Agilent Open Lab software (Agilent OpenLab CDS Chem Station product version A.02.10 [026]) was used for data processing and reporting. Identification of substrate peaks was achieved by comparing retention times with the standards.

\subsection{General Procedure of Dye Synthesis in Large Volume}

Preparative scale reactions were performed in a 500-mL Erlenmeyer flask containing the buffered mixture of an equimolar ratio of substrate A and substrate B1, B2, or B3 using the same concentration of each compound. The transformation mixture was prepared as follows: precursors dissolved in water with the addition of $1 \mathrm{M} \mathrm{NaOH}$ ( $3 \mathrm{mM}$ final concentration of each substrate) were added to the sodium-tartrate buffer solution (5-10 mM final tartaric acid concentration) and then the $\mathrm{pH}$ value of the mixture was adjusted to the optimal $\mathrm{pH}$ value in the range from 4 to $4.5 \mathrm{using} 1 \mathrm{M} \mathrm{NaOH}$. The transformation of the substrates into phenazines was carried out on a rotary shaker $(120 \mathrm{rpm})$ at $28^{\circ} \mathrm{C}$ using LAC with $1 \mathrm{U} / \mathrm{mL}$ final activity.

\subsection{General Procedure for Purification of the $A B 1$ and $A B 3$ Dyes}

At $\mathrm{pH} 4.5$, an orange-red solution of the $\mathrm{AB} 1$ and $\mathrm{AB} 3$ compounds were obtained and lyophilised. The residues were dissolved with methanol. The products were analysed using MERCK HPTLC Silicagel 60 plates and purified using preparative silica gel column chromatography: FLUKA Silicagel $60 \mathrm{~A}$ (200 micron) and a Flash-HPLC system (Gilson, France) (mobile phase: ethyl acetate-MeOH-water: $3: 2: 1, v / v)$ to obtain three fractions for each dye. For both tested dyes, the last red fraction eluted characterised by high intensity of colour was dried under vacuum to obtain the main product of the AB1 and AB3 compounds, i.e., AB1: 10-((2-carboxy-6-methoxyphenyl)amino)-11-methoxy-4-sulfobenzo [a]phenazine-8- carboxylic acid (AB1): red solid; UV-Vis: $495 \mathrm{~nm}$; ES-MS: $548[\mathrm{M}-\mathrm{H}]^{-}$. AB3: 10-((2-carboxy-6-methoxyphenyl)amino)-11-methoxy-5-sulfobenzo [a]phenazine-8-carboxylic acid (AB3): red solid soluble in water; UV-Vis: $505 \mathrm{~nm}$; ES-MS: $548[\mathrm{M}-\mathrm{H}]^{-}$and $550[\mathrm{M}+\mathrm{H}]^{+}, 572[\mathrm{M}+\mathrm{Na}]^{+}$, $1121[2 \mathrm{M}+\mathrm{Na}]^{+}$.

\subsection{General Procedure for Purification of Dye AB2}

At $\mathrm{pH} 4$, an orange/red solution of the AB2 compound was obtained and lyophilised. The residue was dissolved with methanol. The products were analysed using MERCK HPTLC Silicagel 60 plates and purified using preparative silica gel column chromatography: FLUKA Silicagel 60 A (200 micron) and a Flash-HPLC system (Gilson) (mobile phase: ethyl acetate-MeOH-water: 3:2:1, v/v) to obtain four fractions. The last eluted red fraction was dried under vacuum to obtain the AB2 compound, which was identified as a mixture of two compounds: the main product $A B 2 a$ and $A B 2 b$ with different mass spectra. AB2: 10-((2-carboxy-6-methoxyphenyl)amino)-11-methoxybenzo[a]phenazine-8-carboxylic acid: red solid insoluble in water, soluble in 50\% methanol; UV-Vis: $495 \mathrm{~nm}$; ES-MS: $470[\mathrm{M}+\mathrm{H}]^{+}, 456$ $[\mathrm{M}+\mathrm{H}]^{+}$.

\subsection{Molecular Characterisation of Products}

Low-resolution mass spectroscopy analyses were recorded by an LC/MSD chromatography system (1100 Agilent, Waldbronn, Germany) connected to a UV detector. The analyses were performed in a mixture of $\mathrm{MeOH} / \mathrm{H}_{2} \mathrm{O} 95: 5$ at $0.4 \mathrm{~mL} \mathrm{~min}^{-1}$ by direct injection in Electrospray Ionization $\left(N_{2}=\right.$ flow $9 \mathrm{~L} / \mathrm{min}, T=350{ }^{\circ} \mathrm{C}$, solubilisation $p=40 \mathrm{PSI}$, potential difference $\left.=70 \mathrm{eV}\right)$. NMR spectra were performed at $14.1 \mathrm{~T}$ with a Bruker Avance $600 \mathrm{MHz}$ spectrometer at controlled temperatures $\left(25^{\circ} \mathrm{C}\right)$. The solvent is specified for each spectrum. Splitting patterns are designated as s, singlet; $d$, doublet; $\mathrm{t}$, triplet; $\mathrm{q}$, quartet; $\mathrm{m}$, multiplet; br, broad. Chemical shifts (d) are given in ppm relative to the 
resonance of their respective residual solvent peak. FTIR spectra were obtained with an ATRFTIR spectrophotometer (Agilent Technologies Cary 630).

\subsection{Bioactive Properties of Products}

\subsubsection{Chemiluminescence Assay of Antioxidative Activity}

The antioxidant properties of the dyes were assayed using a chemiluminescence method described by Cheng and co-workers [35] based on the measurement of luminescence emitted by the $\mathrm{Fe}^{2+}$-EDTA- $\mathrm{H}_{2} \mathrm{O}_{2}$-luminol system. The reaction mixture contained $50 \mathrm{mM}$ phosphate buffer (pH 7.4), $2 \mathrm{mM}$ luminol in 95\% ethanol, $1.5 \mathrm{mM} \mathrm{Fe}^{2+}$-EDTA solution, and $4.4 \mathrm{mM} \mathrm{H}_{2} \mathrm{O}_{2}$. Samples of the tested dyes $(100 \mu \mathrm{L})$ at concentrations ranging from 0.05 to $2.5 \mathrm{mg} / \mathrm{mL}$ were added to $600 \mu \mathrm{L}$ of phosphate buffer and mixed with $100 \mu \mathrm{L}$ of luminol. In the next step, the samples were placed in the luminometer and $100 \mu \mathrm{L}$ of $\mathrm{FeSO}_{4}$ and $100 \mu \mathrm{L}$ of $\mathrm{H}_{2} \mathrm{O}_{2}$ were added using automatic luminometer dispensers. Standards (vitamin $\mathrm{C}$ and trolox) that are well known for their strong antioxidant activity were used as positive controls. The chemiluminescence peak signals were recorded in the absence $\left(I_{o}\right)$ or presence $\left(I_{1}\right)$ of the tested compounds using a Lumat LB 9506 luminometer (Berthold, Germany) with two dispensers. The inhibitory rate $\left(I_{R}\right)$ was calculated according to the following equation:

$$
I_{R}=\left(1-\frac{I_{1}}{I_{O}}\right) \times 100 \%
$$

The $\mathrm{EC}_{50}$ values of the dyes were calculated using OriginLab software (Northhampton, MS, USA).

\subsubsection{Agar Diffusion Test and Suspension Culture}

The qualitative antibacterial properties of all synthesised compounds (AB1, AB2, AB3) were analysed using an agar diffusion test against reference strains of Gram-positive and Gram-negative bacteria (Staphylococcus aureus ATCC 25923 and Escherichia coli ATCC 25922, respectively). Bacterial inoculum was prepared by adjusting the turbidity of each culture of the bacterium to reach an optical density not exceeding the $0.5 \mathrm{McF}$ arland standard, corresponding to approximately $1-4 \times 10^{8}$ colony-forming units per millilitre $(\mathrm{CFU} / \mathrm{mL})$. The inoculates were diluted in sterile distilled water. Petri dishes (90 mm diameter) containing Mueller-Hinton broth medium (M-H) agar were inoculated with $100 \mu \mathrm{L}$ of the bacterial inoculum. $100 \mu \mathrm{L}$ of the tested compound (concentration of $10 \mathrm{mg} / \mathrm{mL}$ ) were placed into the $9 \mathrm{~mm}$ diameter hole in the centre of the Petri dish. Next, the bacteria were cultivated for $24 \mathrm{~h}$ at $37^{\circ} \mathrm{C}$. For phenazine AB2, which exhibited the highest antimicrobial effect against S. aureus, the quantitative analyses were carried out to obtain the minimal inhibitory concentration (MIC) and the minimum bactericidal concentration (MBC). The tests were performed in a mixture of $200 \mu \mathrm{L}$ of the $\mathrm{M}-\mathrm{H}$ medium and the purified $\mathrm{AB} 2$ dye with concentrations in a range from 0.010 to $4 \mathrm{mg} / \mathrm{mL}$ inoculated with $10 \mu \mathrm{L}$ of the bacterial culture. The bacteria were cultivated for $24 \mathrm{~h}$ at $37^{\circ} \mathrm{C}$ and the cultures were analysed after this time. The lack of turbidity of the bacterial culture indicated the value of the MIC parameter. To obtain the value of the MBC parameter, $10 \mu \mathrm{L}$ of the culture were placed into the sterile $\mathrm{M}-\mathrm{H}$ medium and cultivated for $24 \mathrm{~h}$ at $37^{\circ} \mathrm{C}$. The lack of turbidity of the bacterial culture indicated the value of the MBC parameter.

\subsection{Wool Dyeing}

Wool fabrics for SEM analysis were dyed with the AB2 compound in a bath at a concentration of 5 and $10 \%$ relative to the fibre mass ( 5 or $10 \%$ dye applied omf) and in the presence of $1 \%$ acetic acid. The bath temperature was $100{ }^{\circ} \mathrm{C}$ and the dyeing process lasted $30 \mathrm{~min}$. Afterwards, wool samples were prepared for analysis of the growth inhibition effect against $S$. aureus. Cultures in the mid-exponential growth phase were diluted with LB medium to the cell density of $10^{2} \mathrm{CFU}$ and cultured in the presence of dyed and non-dyed wool fibres overnight. Next day, $20 \mu \mathrm{L}$ of 10,000- and 25,000-times diluted bacterial cultures were inoculated on Petri dishes and cultivated for $24 \mathrm{~h}$. Afterwards, the bacterial 
cells were counted to obtain the inhibition of bacterial growth (\%) in contrast to the control culture without addition of dyed wool. Wool fabrics for colour fastness test were dyed using $1 \%$ solution of AB2 dye and analysed by the TKANLAB Laboratory (Łódź, Poland). The characteristic of wool fabrics: yarn linear mass-warp R63 \pm 4/2 weft R74 \pm 4/2; number of threads per $10 \mathrm{~cm}$-warp $175 \pm 10$, weft $135 \pm 8$; mass per unit area-215 $\pm 10 \mathrm{~g} / \mathrm{m}^{2}$; fat content $-0.8 \pm 0.3 \%$; linen weave.

\subsection{SEM Analysis}

Wool fibres stained with the AB2 dye were fixed in 3\% glutaraldehyde in phosphate buffer (PBS $\mathrm{pH}$ 7.4) for $15 \mathrm{~min}$ at room temperature. After rinsing several times with $0.1 \mathrm{M}$ PBS, the wool fibres were dehydrated in increasing concentrations of ethanol $(25,60,90$, and $100 \%)$ for 5 min in every solution. After rinsing out the alcohol, the samples were dried overnight in a desiccator in the presence of calcium chloride. Finally, the samples were coated with gold in an Emitech K550X Sputter Coater and observed with a TESCAN Vega 3 LMU microscope (Brno-Kohoutovice, Czech Republic).

\section{Conclusions}

In this work, the formation of novel bioactive phenazine compounds in the one-step sustainable and environmentally friendly enzymatic synthesis was described. The known chemical route of phenazine synthesis requires the use of coupling agents and additives that are very often toxic and mutagenic. The proposed laccase-mediated bioconversion of benzoic and naphthalene amino derivatives into bioactive dyes with the phenazine structure showed attractive advantages, including the mild reaction conditions and the short reaction time, compared to the established chemical oxidative methods. The structure and properties of the novel dyes were characterised using a variety of analytical and spectroscopic techniques. During specific tests, one new dye with the tri-molecular phenazine structure and antibacterial activity against Staphylococcus aureus was found. The proposed enzymatic route is a valuable and promising approach for the synthesis of different phenazine dyes with antimicrobial and antioxidative activity.

Supplementary Materials: Supplementary Materials can be found at http://www.mdpi.com/1422-0067/21/6/2052/ s1, Table S1. NMR and FTIR data.

Author Contributions: Conceptualization, J.P.; Data curation, J.P.; Funding acquisition, J.P., K.W.; Investigation, all; Methodology, J.P., K.W., R.P., E.P., M.G., K.S., M.O.-J., J.K.-P., B.P.-P., A.J.-W.; Project administration, J.P.; Resources, J.P., K.W.; Supervision, J.P., A.J.-W.; Validation-M.G.; Visualization, J.P., R.P., E.P., J.K.-P., B.P.-P.; Writing—original draft, J.P., R.P., E.P., A.J.-W.; Writing—review \& editing, J.P., R.P., A.J.-W. All authors have read and agreed to the published version of the manuscript.

Funding: This research was funded by National Science Centre (Poland), grant number 2016/21/D/NZ9/02460, 2015/17/N/NZ9/03647 and the Ministry of Science and Higher Education Iuventus Plus Program (0433/IP1/2011/71).

Acknowledgments: E.P. thanks the Italian Ministero dell'Istruzione, dell'Università e della Ricerca (MIUR) for financial support (PRIN2015LZE994). MIUR is also acknowledged for financial support through the program "Dipartimenti di Eccellenza-2018-2022".

Conflicts of Interest: The authors declare no conflict of interest. The funders had no role in the design of the study; in the collection, analyses, or interpretation of data; in the writing of the manuscript, or in the decision to publish the results.

\section{Abbreviations}

$\begin{array}{ll}\text { LAC } & \text { Laccase } \\ \text { omf } & \text { on mass fibre } \\ \text { MIC } & \text { Minimal Inhibitory Concentration } \\ \text { SEM } & \text { Scanning Electron Microscope }\end{array}$

\section{References}

1. Rodriguez Couto, S.; Toca Herrera, J.L. Industrial and biotechnological applications of laccases: A review. Biotechnol. Adv. 2006, 24, 500-513. [CrossRef] [PubMed] 
2. Mate, D.M.; Alcalde, M. Laccase: A multi-purpose biocatalyst at the forefront of biotechnology. Microb. Biotechnol. 2016, 10, 1457-1467. [CrossRef] [PubMed]

3. Mikolasch, A.; Schauer, F. Fungal laccase as tools for the synthesis of new hybrid molecules and biomaterials. App. Microbiol. Biotechnol. 2009, 82, 605-624. [CrossRef] [PubMed]

4. Blankenfeldt, W.; Parsons, J.F. The structural biology of phenazine biosynthesis. Curr. Opin. Struc. Biol. 2014, 29, 26-33. [CrossRef] [PubMed]

5. Laursen, J.B.; Nielsen, J. Phenazine natural products: biosynthesis, synthetic analogues, and biological activity. Chem. Rev. 2004, 104, 1663-1686. [CrossRef] [PubMed]

6. Hayden, C.; Bryant, J.J.; Mackey, M.A.; Höfer, K.; Lindner, B.D.; Nguyen, V.P.; Jäschke, A.; Bunz, U.H. Antimicrobial activity of water-soluble triazole phenazine clickamers against $E$ coli. Chem. Eur. J. 2014, 20, 719-723. [CrossRef]

7. Guttenberger, N.; Blankenfeldt, W.; Breinbauer, R. Recent developments in the isolation, biological function, biosynthesis, and synthesis of phenazine natural products. Bioorg. Med. Chem. 2017, 25, 6149-6166. [CrossRef]

8. Krishnaiah, M.; Rodrigues de Almeida, N.; Udumula, V.; Song, Z.; Chhonker, Y.S.; Abdelmoaty, M.M.; Aragao do Nascimento, V.; Murry, D.J.; Conda-Sheridan, M. Synthesis, biological evaluation, and metabolic stability of phenazine derivatives as antibacterial agents. Eur. J. Med. Chem. 2018, 143, 936-947. [CrossRef]

9. Smitka, T.A.; Bunge, R.H.; Wilton, J.H.; Hokanson, G.C.; French, J.C. PD 116,152, a new phenazine antitumor antibiotic. Structure and antitumor activity. J. Antibiot. (Tokyo) 1986, 39, 800-803. [CrossRef]

10. Mahran, A.M.; Ragab, S.S.; Hashem, A.I.; Ali, M.M.; Nada, A.A. Synthesis and antiproliferative activity of novel polynuclear heterocyclic compounds derived from 2,3-diaminophenazine. Eur. J. Med. Chem. 2015, 90, 568-576. [CrossRef]

11. Polak, J.; Jarosz-Wilkołazka, A.; Szałapata, K.; Graz, M.; Osińska-Jaroszuk, M. Laccase-mediated synthesis of a phenoxazine compound with antioxidative and dyeing properties-the optimisation process. New Biotechnol. 2016, 33, 255-262. [CrossRef] [PubMed]

12. Alonso, M.; Horcajada, R.; Groombridge, H.J.; Chudasama (née Mandalia), R.; Motevalli, M.; Utley, J.H.; Wyatt, P.B. Synthesis of phenazine derivatives for use as precursors to electrochemically generated bases. Org. Biomol. Chem. 2005, 3, 2832-2841. [CrossRef] [PubMed]

13. Forte, S.; Polak, J.; Valensin, D.; Taddei, M.; Basosi, R.; Vanhulle, S.; Jarosz-Wilkołazka, A.; Pogni, R. Synthesis and structural characterization of a novel phenoxazinone dye by use of a fungal laccase. J. Mol. Catal. B Enzym. 2010, 63, 3-4. [CrossRef]

14. Bruyneel, F.; Enaud, E.; Billottet, L.; Vanhulle, S.; Marchand-Bryneart, J. Regioselective synthesis of 3-hydroxyorthanilic acid and its biotransformation into a novel phenoxazinone dye by use of laccase. Eur. J. Org. Chem. 2008, 2008, 72-79. [CrossRef]

15. Sousa, A.C.; Conceição Oliveira, M.; Martins, L.O.; Robalo, M.P. Towards the rational biosynthesis of substituted phenazines and phenoxazinones by laccases. Green Chem. 2014, 16, 4019-4030. [CrossRef]

16. Sousa, A.C.; Oliveira, M.C.; Martins, L.O.; Robalo, M.P. A sustainable synthesis of asymmetric phenazines and phenoxazinones mediated by CotA-laccase. Adv. Synth. Catal. 2018, 360, 575-583. [CrossRef]

17. Hahn, V.; Davids, T.; Lalk, M.; Schauer, F.; Mikolasch, A. Enzymatic cyclizations using laccases: Multiple bond formation between dihydroxybenzoic acid derivatives and aromatic amines. Green Chem. 2010, 12, 879-887. [CrossRef]

18. Singh, R.; Jain, A.; Panwar, S.; Gupta, D.; Khare, S.K. Antimicrobial activity of some natural dyes. Dyes Pigm. 2005, 66, 99-102. [CrossRef]

19. Widsten, P.; Healthcote, C.; Kandelbauer, A.; Guebitz, G.; Nyanhongo, G.S.; Prasetyo, E.N.; Kudanga, T. Enzymatic surface functionalisation of lignocellulosic materials with tannins for enhancing antibacterial properties. Process Biochem. 2010, 45, 1072-1081. [CrossRef]

20. Jeon, J.-R.; Baldrian, P.; Murugesen, K.; Chang, Y.-S. Laccase-catalysed oxidations of naturally occurring phenols: From in vivo biosynthetic pathways to green synthetic applications. Microb. Biotechnol. 2012, 5, 318-332. [CrossRef]

21. Ghaheh, F.S.; Mortazavi, S.M.; Alihosseini, F.; Fassihi, A.; Nateri, A.S.; Abedi, D. Assessment of antibacterial activity of wool fabrics dyed with natural dyes. J. Clean. Prod. 2014, 72, 139-145. [CrossRef] 
22. Mikolasch, A.; Wurster, M.; Lalk, M.; Witt, S.; Seefeldt, S.; Hammer, E.; Schauer, F.; Jülich, W.D.; Lindequist, U. Novel beta-lactam antibiotics synthesized by amination of catechols using fungal laccase. Chem. Pharm. Bull. 2008, 56, 902-907. [CrossRef] [PubMed]

23. Mikolasch, A.; Hildebrandt, O.; Schlüter, R.; Hammer, E.; Witt, S.; Lindequist, U. Targeted synthesis of novel $\beta$-lactam antibiotics by laccase-catalyzed reaction of aromatic substrates selected by pre-testing for their antimicrobial and cytotoxic activity. Appl. Microbiol. Biotechnol. 2016, 100, 4885-4899. [CrossRef] [PubMed]

24. Polak, J.; Jarosz-Wilkolazka, A.; Szuster-Ciesielska, A.; Wlizlo, K.; Kopycinska, M.; Sojka-Ledakowicz, J.; Lichawska-Olczyk, J. Toxicity and dyeing properties of dyes obtained through laccase-mediated synthesis. J. Clean. Prod. 2016, 112, 4265-4272. [CrossRef]

25. Polak, J.; Jarosz-Wilkołazka, A. Structure/redox potential relationship of simple organic compounds as potential precursors of dyes for laccase-mediated transformation. Biotechnol. Progr. 2012, 23, 93-102. [CrossRef]

26. Polak, J.; Jarosz-Wilkolazka, A. Fungal laccases as green catalysts for dye synthesis. Process Biochem. 2012, 47, 1295-1307. [CrossRef]

27. Wlizło, K.; Polak, J.; Jarosz-Wilkolazka, A.; Pogni, R.; Petricci, E. Novel textile dye obtained through transformation of 2-amino-3-methoxybenzoic acid by free and immobilised laccase from a Pleurotus ostreatus strain. Enz. Microb. Technol. 2020, 132, 109398. [CrossRef]

28. Sousa, A.C.; Piedade, M.F.M.; Martins, L.O.; Robalo, M.P. Eco-friendly synthesis of indo dyes mediated by a bacterial laccase. Green Chem. 2016, 18, 6063-6070. [CrossRef]

29. $\mathrm{Xu}, \mathrm{F}$. Effects of redox potential and hydroxide inhibition on the $\mathrm{pH}$ activity profile of fungal laccases. J. Biol. Chem. 1997, 272, 924-928. [CrossRef]

30. Shleev, S.; Klis, M.; Wang, Y.; Rogalski, J.; Bilewicz, R.; Gorton, L. Comparative spectroelectrochemical studies of lyophilized and nonlyophilized laccases from Cerrena unicolor basidiomycete. Electroanalysis 2007, 19, 1039-1047. [CrossRef]

31. Shahid, M.; Mohammad, F.; Chen, G.; Tang, R.C.; Xing, T. Enzymatic processing of natural fibers: White biotechnology for sustainable development. Green Chem. 2016, 18, 2256-2281. [CrossRef]

32. Luterek, J.; Gianfreda, L.; Wojtaś-Wasilewska, M.; Rogalski, J.; Jaszek, M.; Malarczyk, E.; Dawidowicz, A.; Ginalska, G.; Leonowicz, A.; Finks-Boots, M. Screening of the wood rotting fungi for laccase production: Induction by ferulic acid, partial purification, and immobilization of laccase from the high laccase-producing strain, Cerrena unicolor. Acta Microbiol. Pol. 1997, 46, 297-311.

33. Wolfenden, B.S.; Willson, R.L. Radical-cations as reference chromogens in kinetic studies of ono-electron transfer reactions: Pulse radiolysis studies of 2,2'-azinobis-(3-ethylbenzthiazoline-6-sulphonate). J. Chem. Soc. Perkin. Trans. 1982, 2, 805-812. [CrossRef]

34. Bernhardt, F.-H.; Staudinger, H.; Ulrich, V. The properties of p-anisate O-demethylase in cell-free extracts of Pseudomonas sp. Hoppe-Seyler's Z. Physiol. Chem. 1970, 351, 467-478. [CrossRef] [PubMed]

35. Cheng, Z.; Yan, G.; Li, Y.; Chang, W. Determination of antioxidant activity of phenolic antioxidants in a Fenton-type reaction system by chemiluminescence assay. Anal. Bioanal. Chem. 2003, 375, 376-380. [CrossRef]

(C) 2020 by the authors. Licensee MDPI, Basel, Switzerland. This article is an open access article distributed under the terms and conditions of the Creative Commons Attribution (CC BY) license (http://creativecommons.org/licenses/by/4.0/). 